\title{
Gastrointestinal lymphomas - A clinicopathological study in a tertiary care centre
}

\author{
T. Rajeswari ${ }^{1}$, V. Rajalakshmi ${ }^{2, *}$ \\ ${ }^{\mathbf{1}}$ Assistant Professor, ${ }^{2}$ Professor \& HOD, Dept. of Pathology, ESIC Medical College \& PGIMSR, Chennai, Tamil Nadu, India
}

*Corresponding Author:

Email: raji_path@ rediffmail.com

\begin{abstract}
Introduction: The aim of this study was to review the clinicopathological features of lymphomas of stomach and intestine, reported in a tertiary care hospital, for a period of two years. Among the total 454 reported cases of gastrointestinal malignancies, 60 cases were categorized as poorly differentiated neoplasms of stomach and intestine, were included in the study. Immunohistochemical analysis was done in all cases, by using carcinoembryonic antigen, CD 20, synaptophysin and chromogranin A. Results were analysed, in the total 60 cases of poorly differentiated malignancies, 12 cases were proved to be B - cell non-Hodgkins lymphomas with the stomach being the most common site.
\end{abstract}

Keywords: Gastrointestinal malignancies, Poorly differentiated neoplasms, Carcinoembryonic antigen, CD20, Poorly differentiated adenocarcinomas, Non-Hodgkins lymphomas.

\section{Introduction}

The gastrointestinal tract is a remarkably dynamic organ system with complex secretory, absorptive and motility functions. Furthermore, the mucosal surface is characterised by a very rapid turnover of the epithelial cell population, creating inherently the setting for a variety of neoplastic disorders.

Tumors of the gastrointestinal tract are varied, yet can often prove to be diagnostically challenging. When considering poorly differentiated malignancies which are categorised as tumors with poor prognosis, it is mandatory to give specific diagnosis to select appropriate therapeutic strategy and to predict prognosis. Understanding the unique immunohistochemical profiles of each tumor entity will greatly aid in the diagnoses of these tumors.

Histopathological diagnosis, tumor classification and identification of histogenesis of metastases of unknown or uncertain primary tumors are considered to be the most important responsibilities of histopathologists. At present in addition to the traditional light microscopy, there is a list of other definite methods that support histopathologists in their work such as, immunohistochemistry and molecular diagnosis.

Immunohistochemistry (IHC), is a method, the one which microscopically recognizes cellular contents by using antibodies that are specific, has very much improved the field of surgical pathology by empowering the hematoxylin and eosin staining. ${ }^{1}$ In diagnosing the suspected poorly differentiated malignancies and tumors of unknown origin, IHC is very useful in detecting the origin of the tumor at the cellular level, with the help of antibodies that are specific to tissues. This enables the pathologists to diagnose the tumors accurately. Results of the immunohistochemical methods should be studied and analysed, based on the light microscopic hematoxylin and eosin stained sections. Immunohistochemistry gives important and useful information regarding the behaviour of the tumor.

In the past 20 years IHC has expanded leaps and bounds and has become a very powerful as well as simple tool in diagnostic histopathology ${ }^{1}$. Nowadays the methods of immunohistochemical procedures have been modified and simplified to the level, such that it can be done in almost all the laboratories. Many a number of newer diagnostic antibodies are introduced regularly to resolve diagnostic problems and to improve the diagnostic accuracy.

As the size of biopsies decrease, particularly in gastrointestinal tract lesions the role of immunohistochemical stains will become even more important in determining the site of origin and differentiation of these tumors. ${ }^{1}$

This study, analysed the clinicopathological features of gastric and intestinal lymphomas along with the immunohistochemical profile of poorly differentiated tumors of stomach and intestine.

\section{Materials and Methods}

This prospective study was conducted in the Department of Pathology, in a tertiary care hospital. After approval from the institutional ethics committee, a total of 60 cases of poorly differentiated gastric and intestinal malignancies were included in the study design. In all patients, the clinical data, including age, sex, occupation, personal history, clinical history, endoscopic findings, anatomic site and operative findings were obtained from the medical records.

Among the 60 specimens, 54 were biopsies and 6 were resected specimens. All the specimens received were fixed in $10 \%$ neutral formalin for $18-24$ hours. Detailed gross examination of the specimens were done. Representative samples were taken. Majority of specimens were endoscopic small biopsies, approximately $0.1 \mathrm{cc}$ to $0.3 \mathrm{cc}$, embedded in total. The 
tissues were processed in various grades of alcohol and xylol using automated histokinette.

Histopathological study was done in all the specimens as per standard guidelines. Immunohistochemical analysis was done in all 60 cases using carcinoembryonic antigen, CD 20, synaptophysin and chromogranin A to diagnose poorly differentiated adenocarcinomas, lymphomas and neuroendocrine carcinomas.

\section{Results}

454 cases of gastrointestinal malignancies were reported during the study period. Of these, 60 cases $(13.21 \%)$ were categorised as poorly differentiaed neoplasms of stomach and intestine (Chart 1).

The 60 cases consisted of 39 males and 21 females, and the age ranged from $19-85$ years with a median of 56 years. Of the 60 cases, 51 cases $(85 \%)$ were gastric poorly differentiated neoplasms, 2 cases $(3.33 \%)$ were small intestinal poorly differentiated neoplasms, 7 cases $(11.66 \%)$ were large intestinal poorly differentiated malignancies (Chart 2). Based on immunohistochemical analysis, out of total 60 cases, 46 cases $(76.67 \%)$ were poorly differentiated adenocarcinomas, 2 cases $(3.33 \%)$ were neuroendocrine carcinomas (NEC), 12 cases (20\%) were non Hodgkins lymphomas (NHL) (Chart $3)$.

Among the total cases of lymphomas, stomach was the predominant site $(58.33 \%)$, followed large intestine (25\%) and small intestine (16.67\%) (Chart 4). Lymphomas occurred from second decade to eighth decade. More number of cases (4/12) were in the sixth decade of life. The observed male, female ratio was 1 : 1 .

Totally 7 cases of gastric lymphomas were diagnosed by immunohistochemical analysis. Lymphomas of stomach were seen from nineteen years to seventy five years, with the median age of 59 years. Male: female ratio was 3:4. Most lymphomas occurred in antrum of stomach (4/7) (Table 1).

Two cases of B - cell small intestinal lymphomas, diagnosed in 22 years old male involving duodenum and in 49 years old female with jejunum involvement (Table 2).

Three cases of large intestinal lymphomas were (male: female $=2: 1$, age range $50-77$ years, median 56 years) diagnosed in this study, each one located in ascending colon, sigmoid and rectum respectively (Table 3).

All lymphomas of gastric and intestinal region, proved to be of B - cell type (Fig. 1 -10).

\section{Discussion}

The gastrointestinal tract (GIT) tumors are heterogeneous group of lesions with varied architecture, pattern of growth, cell differentiation, and histogenesis. It is wise to mention that these tumors share many characteristics, making definitive diagnosis a very challenging one. Since the histological type of each and every tumor is important for assessing staging, deciding treatment protocols and prognosis, it highlights the strong role of pathologists who should use all available resources and recent advances, along with light microscopy to arrive at a definitive final diagnosis.

Poorly differentiated types of gastric and intestinal malignancies are generally more spreading in nature, locally, to the surrounding structures and to the distant organs, very rapidly with reducing the survival of patients when compared with differentiated types. ${ }^{2}$

In this study, among all GIT specimens received between july 2011 to july 2013, 454 GIT carcinomas were diagnosed. Among the total, 60 cases were reported as poorly differentiated malignancies of stomach and Intestine. These cases were analysed for clinicopathological features and immunohistochemical studies by using carcinoembryonic antigen (CEA) and CD 20, synaptophysin and chromogranin A.

Among the total 60 cases of poorly differentiated malignancies, 12 cases were confirmed as nonHodgkins lymphomas as per immunohistochemical analysis. These 12 cases were studied, according to the anatomical location, age distribution, gender, clinical presentation, and cell of origin.

In the present study, the most common location affected was stomach (7/12), least common site was small intestine (2/12). These findings, being compatible with other related observations - 1.TADASHI TERADA $^{3}$ studies on gastrointestinal malignant lymphoma - a pathological study of 37 cases in a single institution, which was published in American Journal of Blood Research on 2012, 2. LEWIN ET AL ${ }^{4}$ studies on 117 cases of gastrointestinal lymphomas (Table 4).

Site of origin of gastrointestinal lymphomas and also the histological subtypes differs between races and geographical population. In western countries gastrointestinal lymphomas predominantly involves stomach and only small number of cases occurring in intestine. For example, a study from $\mathrm{UK}^{5}$ showed that the most common location of lymphoma is stomach $(63 \%)$, followed in order by small intestine $(23 \%)$ and large intestine (13\%).

NAKAMURA ET $\mathrm{AL}^{6}$ in Kyushu University of Japan concluded, based on his study on 455 gastrointestinal lymphoma patients that stomach being involved in 342 cases (75\%), intestine in 96 cases $(22 \%)$, stomach and intestine in 17 cases $(4 \%)$. The intestinal lymphomas involved small intestine in 72 cases, and large intestine in 24 cases. This is similar to the present study.

Other studies conducted in oriental countries such as Hong Kong, ${ }^{7}$ Thailand ${ }^{8}$ and India ${ }^{9}$ regarding the location of these lymphomas, also shows that, the stomach being commonly affected. In Middle East countries,,$^{10}$ intestine was the most common site of these lymphomas, it may be due to racial and geographical preference. 
We also noted positive correlation, regarding the male and female cases distribution of gastric and intestinal lymphomas (Table 5).

In Tadashi Terada studies, ${ }^{3}$ they used CD10, CD20 and $\mathrm{CD} 79 \alpha$ as B-cell markers, CD3 and CD45RO as Tcell markers, and CD56 as NK cell marker. This study utilised CD 20 as a B - cell marker. The finding of most common gastrointestinal lymphomas are of B cell type, being compatible with other studies ${ }^{11-14}$ (Table 6). The most common clinical presentation noted was abdominal pain (9/12), being compatible with TADASHI TERADA STUDIES ${ }^{3}$ (15/37).

The incidence, cell of origin and predominance of antral involvement of gastric lymphomas of this present study very well correlated with other related studies. ${ }^{3}$ (Table 7).

On the basis of incidence and cell of origin of small intestinal lymphomas, our study very well correlated with TADASHI TERADA STUDIES $^{3}$ (Table 8). At this time, It is wise to mention about the article published in International journal of clinical and experimental pathology by the same author TADASHI TERADA $^{15}$ on small intestinal lymphomas. This study was conducted in 2012 with 1312 number of patients, observed that the incidence was $0.5 \%$. All cases were located in ileum. Lymphomas were observed more in females. Of the total 6 cases, 4 were B - cell type, 2 were $\mathrm{T}$ - cell type.

When we consider TADASHI TERADA STUDIES $^{3}$, our present study very well correlated on the grounds of incidence, male: female ratio and cell of origin of large intestinal lymphomas (Table 9).

In summary, this study assessed the role of immunohistochemistry in the diagnosis of poorly differentiated gastric and intestinal malignancies and also analysed the demographic profile and clinicopathological aspects of gastric and intestinal lymphomas.

\section{Chart 1: Incidence of poorly differentiated malignancies (PDM) of stomach}

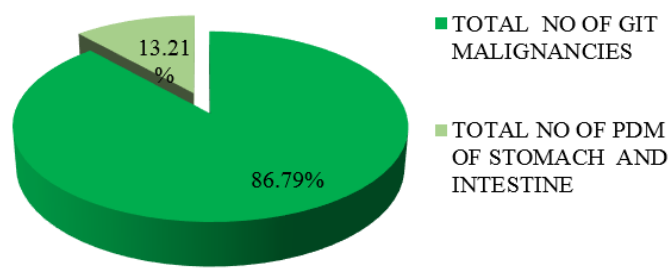

\section{Chart 2: Distribution of poorly differentiated malignancies of stomach}

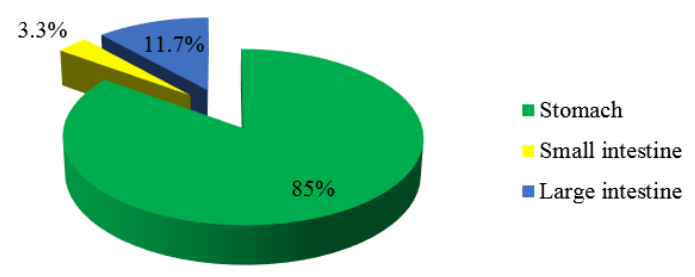

Chart 3: Distribution of poorly differentiated malignancies of stomach and intestine according to immunohistochemical analysis

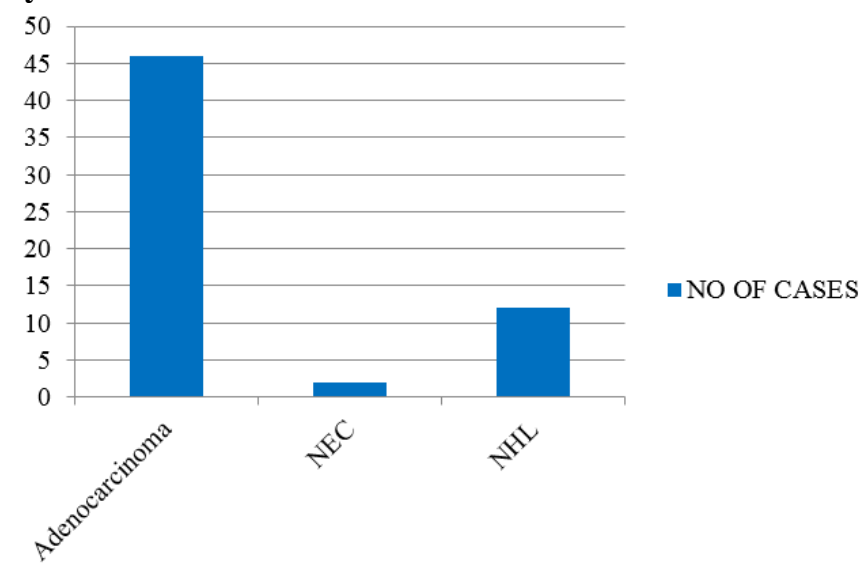


Chart 4 : Distribution of lymphomas of stomach and intestine according to location DISTRIBUTION OF LYMPHOMAS OF STOMACH AND INTESTINE ACCORDING TO LOCATION

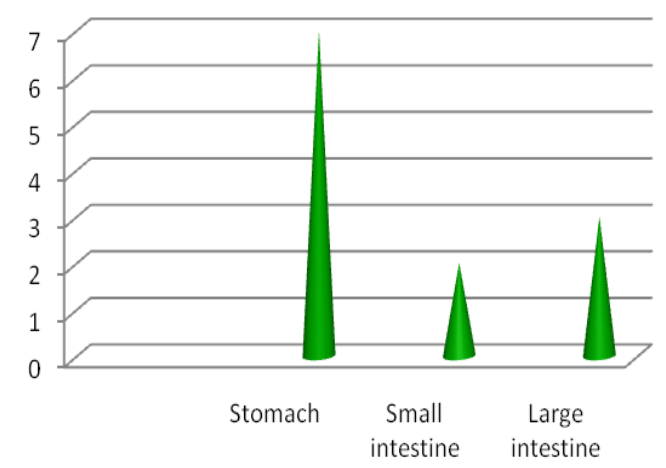

- NOOF CASES

Table 1: Distribution of lymphomas of stomach according to clinicopathological features

\begin{tabular}{|l|c|}
\hline \multicolumn{1}{|c|}{ Variables } & Features \\
\hline Total No Cases & 7 \\
\hline Male & 3 \\
\hline Female & 4 \\
\hline Age Range & $19-75$ years \\
\hline Median Age & 59 years \\
\hline Location & Body -3, \\
& Antrum -4 \\
\hline Cell of Origin & All are B - Cell type \\
\hline
\end{tabular}

Table 2: Distribution of lymphomas of small intestine according to clinicopathological features

\begin{tabular}{|c|c|}
\hline Variables & Features \\
\hline Total no cases & 2 \\
\hline Male & 1 \\
\hline Female & 1 \\
\hline Age range & $22-49$ years \\
\hline Mean age & 35 years \\
\hline Location & $\begin{array}{c}\text { Duodenum }-1, \\
\text { Jejunum }-1\end{array}$ \\
\hline Cell of origin & Both B - Cell type \\
\hline
\end{tabular}

Table 3: Distribution of lymphomas of large intestine according to clinicopathological features

\begin{tabular}{|c|c|}
\hline Variables & Features \\
\hline Total no cases & 3 \\
\hline Male & 2 \\
\hline Female & 1 \\
\hline Age range & $50-77$ years \\
\hline Median age & 56 years \\
\hline Location & $\begin{array}{c}\text { Ascending colon }-1, \\
\text { Sigmoid }-1, \text { Rectum }-1\end{array}$ \\
\hline Cell of origin & All B - Cell type \\
\hline
\end{tabular}

Table 4: Lymphomas of stomach and intestine comparison according to the location of lymphomas

\begin{tabular}{|l|c|c|c|}
\hline \multicolumn{1}{|c|}{ Location } & $\begin{array}{c}\text { Present } \\
\text { Study }\end{array}$ & $\begin{array}{c}\text { Lewin et al } \\
\text { Studies }^{\mathbf{4}}\end{array}$ & $\begin{array}{c}\text { Tadashi Terada } \\
\text { Studies (2012) }\end{array}$ \\
\hline Stomach & $58.33 \%$ & $41.03 \%$ & $68 \%$ \\
\hline Small intestine & $16.67 \%$ & $31.63 \%$ & $16 \%$ \\
\hline Large intestine & $25 \%$ & $9.40 \%$ & $16 \%$ \\
\hline
\end{tabular}


Table 5: Lymphomas of stomach and intestine according to age and gender distribution

\begin{tabular}{|l|c|c|}
\hline \multicolumn{1}{|c|}{ Variables } & Present Study & $\begin{array}{c}\text { Tadashi Terada } \\
\text { Studies (2012) }\end{array}$ \\
\hline Age range & $19-77$ years & $46-89$ years \\
\hline Median age & 56 years & 69 years \\
\hline Male & $50 \%$ & $54.05 \%$ \\
\hline Female & $50 \%$ & $45.95 \%$ \\
\hline
\end{tabular}

Table 6: Lymphomas of stomach and intestine comparison according to cell type (B cell / $\mathrm{T}$ cell)

\begin{tabular}{|c|c|c|c|}
\hline Cell Type & $\begin{array}{c}\text { Present } \\
\text { Study }\end{array}$ & $\begin{array}{c}\text { Grody et al } \\
\text { Studies }^{12}\end{array}$ & $\begin{array}{l}\text { Tadashi Terada } \\
\text { Studies }(2012)^{3}\end{array}$ \\
\hline $\mathrm{B}-$ cell & $100 \%$ & $84 \%$ & $95 \%$ \\
\hline $\mathrm{T}-$ cell & $0 \%$ & & $5 \%$ \\
\hline
\end{tabular}

Table 7: Gastric lymphomas comparison based on clinicopathological features

\begin{tabular}{|l|c|c|}
\hline \multicolumn{1}{|c|}{ Variables } & Present Study & $\begin{array}{c}\text { Tadashi Terada } \\
\text { Studies }^{\mathbf{3}}\end{array}$ \\
\hline Incidence & $58.33 \%$ & $67.57 \%$ \\
\hline Male, Female ratio & $1.5: 2$ & $14: 11$ \\
\hline Age range & $19-75$ years & $46-84$ years \\
\hline Median age & 59 years & 70 years \\
\hline Location & $\begin{array}{c}\text { Antrum }-4, \\
\text { body }-3 \\
\text { ratio }-1: 1\end{array}$ & $\begin{array}{c}\text { Antrum }-17, \\
\text { body }-8 \\
\text { ratio }-2: 1\end{array}$ \\
\hline b - Cell type & $\begin{array}{c}\text { All cases are B } \\
\text { - cell type }\end{array}$ & $\begin{array}{c}\text { All cases are } \\
\text { B - cell type }\end{array}$ \\
\hline T - Cell type & Nil & Nil \\
\hline
\end{tabular}

Table 8: Small intestinal lymphomas comparison based on clinicopathological features

\begin{tabular}{|l|c|c|}
\hline \multicolumn{1}{|c|}{ Variables } & Present Study & $\begin{array}{c}\text { Tadashi Terada } \\
\text { Studies }^{3}\end{array}$ \\
\hline Incidence & $16.67 \%$ & $16.22 \%$ \\
\hline Male: Female ratio & $1: 1$ & $1: 2$ \\
\hline Age range & $22-49$ years & $49-89$ years \\
\hline Median age & 35 years & 70 years \\
\hline Location & $\begin{array}{c}\text { Duodenum }-1, \\
\text { Jejunum }-1\end{array}$ & Ileum \\
\hline B - Cell type & $\begin{array}{c}\text { All cases are B } \\
\text { - Cell type }\end{array}$ & 4 \\
\hline T - Cell type & Nil & 2 \\
\hline
\end{tabular}

Table 9: Large intestinal lymphomas comparison based on clinicopathological features

\begin{tabular}{|l|c|c|}
\hline \multicolumn{1}{|c|}{ Variables } & Present Study & $\begin{array}{c}\text { Tadashi Terada } \\
\text { Studies }^{3}\end{array}$ \\
\hline Incidence & $25 \%$ & $16.22 \%$ \\
\hline $\begin{array}{l}\text { Male }: \\
\text { Female ratio }\end{array}$ & $2: 1$ & $2: 1$ \\
\hline Age range & $50-77$ years & $69-86$ years \\
\hline Median age & 56 years & 74 years \\
\hline Location & $\begin{array}{c}\text { Ascending colon }-1 \\
\text { Sigmoid }-1 \\
\text { Rectum }-1\end{array}$ & $\begin{array}{c}\text { Ascending colon }-1 \\
\text { Sigmoid }-3 \\
\text { Rectum }-2\end{array}$ \\
\hline B - Cell type & All are B - Cell type & All are B - Cell type \\
\hline T - Cell type & Nil & Nil \\
\hline
\end{tabular}




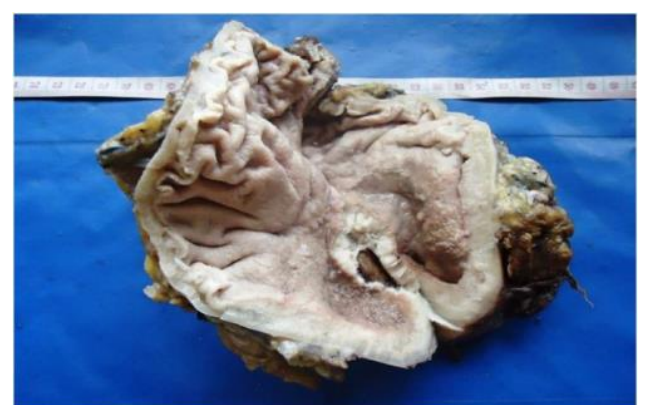

Fig. 1: 773 / 12 - Stomach - diffuse thickening in antrum

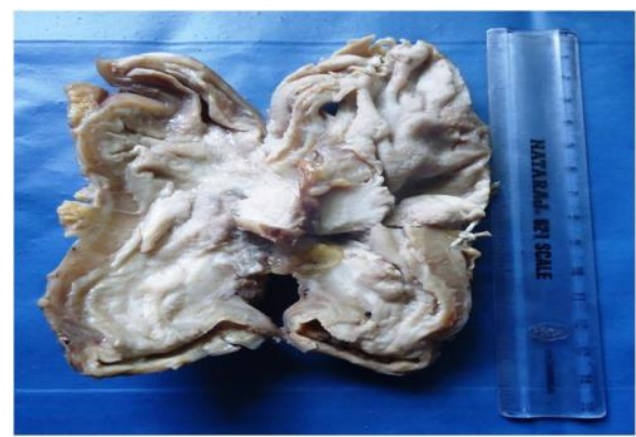

Fig. 2: 763 / 13 - Infiltrative growth in body of stomach

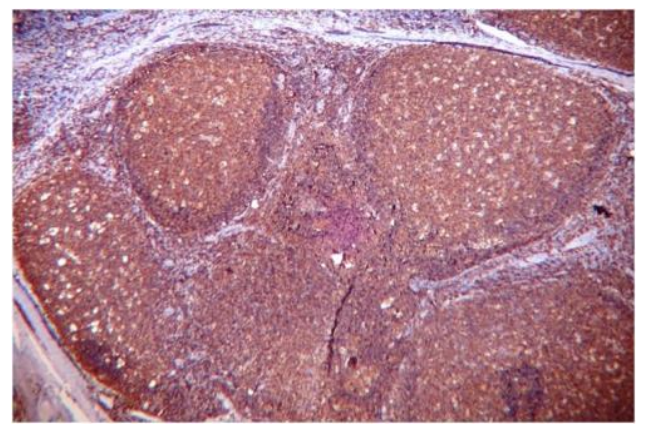

Fig. 3: CD 20 - Positive control - 4x - lymphnode

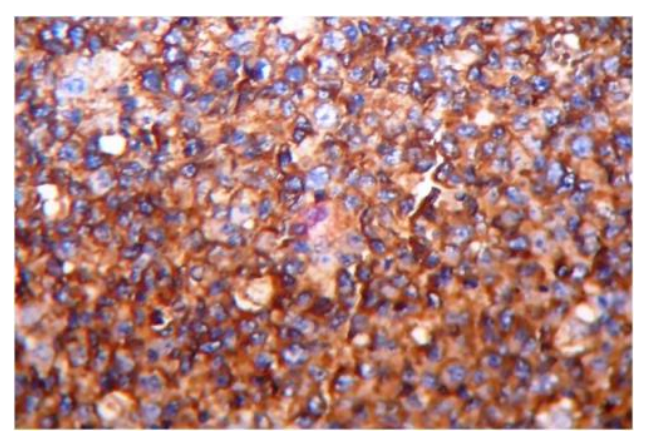

Fig. 4: CD 20 - 40 $x$ - positive control - lymphnode - cytoplasmic posivity

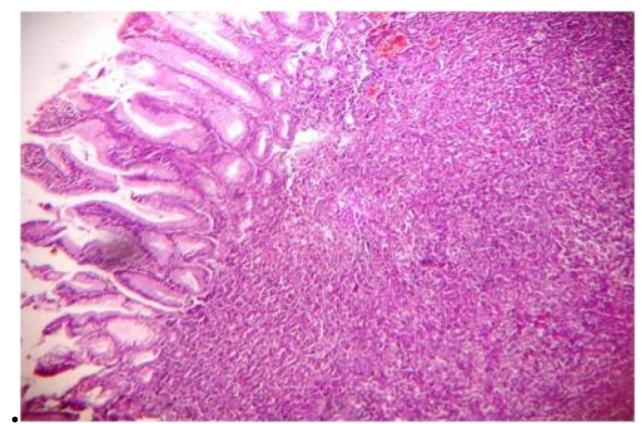

Fig. 5: 773 / $12-4 x-$ poorly differentiated malignancy - stomach

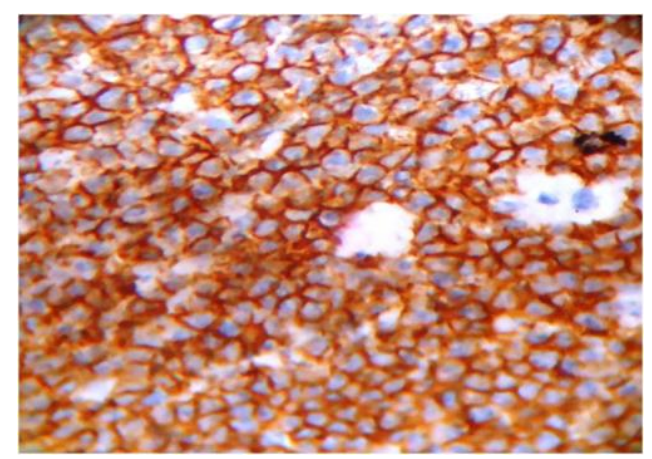

Fig. 6: 773 / $12-40 x-$ CD 20 positive

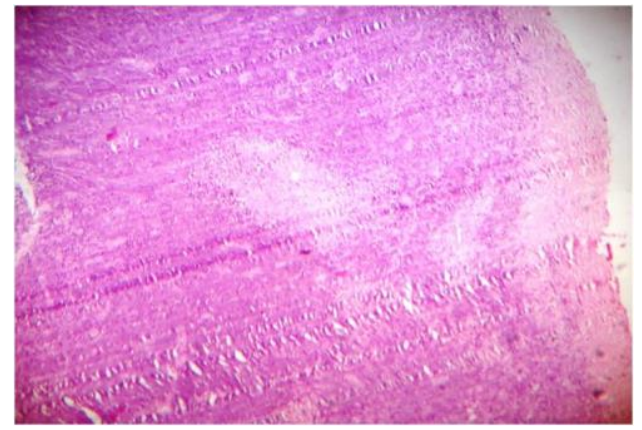

Fig. 7: 763 / $13-4 x-$ poorly differentiated malignancy

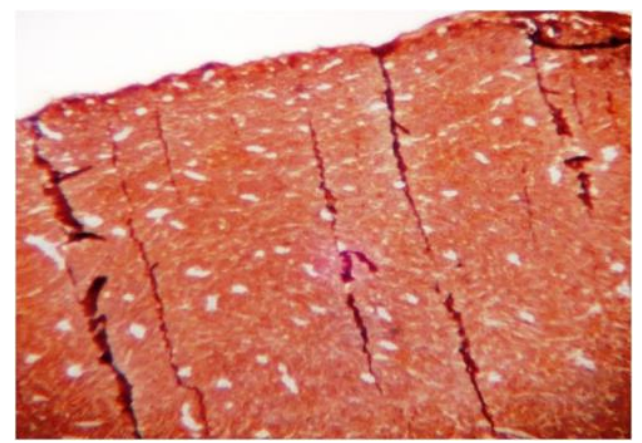

Fig. 8: 763 / $12-4 x-C D 20$ positive 


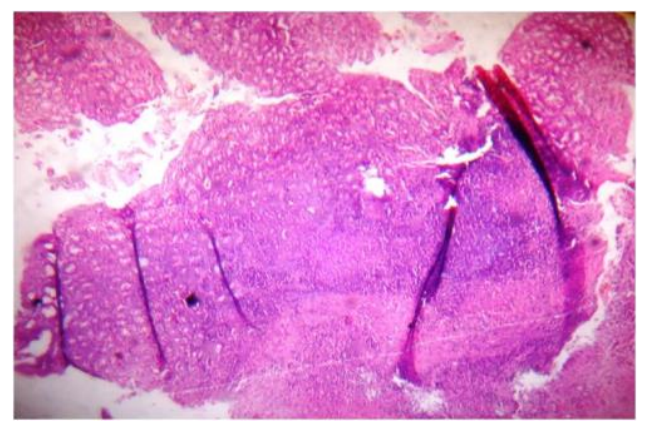

Fig. 9: 557 / $12-4 x-$ poorly differentiated malignancy - stomach

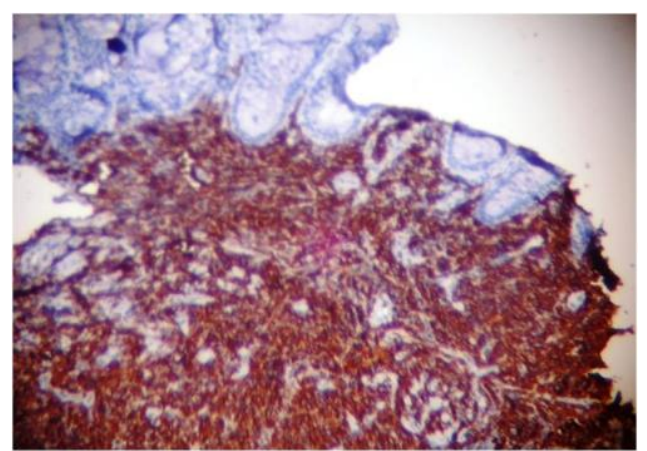

Fig. 10: 557 / 12 - $40 x-$ CD 20 - positive

Funding: No funding sources.

Conflict of interest: None declared.

\section{References}

1. Wong HH, Chu P. Immunohistochemical features of the gastrointestinal tract tumors. $J$ Gastrointest Oncol 2012;3(3):262.

2. Lee HH, Song KY, Park CH, Jeon HM. Undifferentiatedtype gastric adenocarcinoma: prognostic impact of three histological types. World J Surg Oncol 2012;10(1):254.

3. Terada T. Gastrointestinal malignant lymphoma: a pathologic study of 37 cases in a single Japanese institution. Am J Blood Res 2012;2(3):194.

4. Lewin KJ, Ranchod M, Dorfman RF. Lymphomas of the gastrointestinal tract. A study of 117 cases presenting with gastrointestinal disease. Cancer 1978;42(2):693-707.
5. Koh P, Horsman J, Radstone C, Hancock H, Goepel J, Hancock B. Localised extranodal non-Hodgkin's lymphoma of the gastrointestinal tract: Sheffield Lymphoma Group experience (1989-1998). Int J Oncol 2001;18(4):743-48.

6. Nakamura T, Yao T, Niho Y, Tsuneyoshi M. A clinicopathological study in young patients with gastric carcinoma. J Surg Oncol 1999;71(4):214-19.

7. Liang R, Todd D, Chan T, Chiu E, Lie A, Kwong YL, et al. Prognostic factors for primary gastrointestinal lymphoma. Hematological Oncol 1995;13(3):153-63.

8. Sukpanichnant S. Analysis of 1983 cases of malignant lymphoma in Thailand according to the World Health Organization classification. Human Pathol 2004;35(2):224-30.

9. Ramesh Chandran R, Hemanth Raj E, Chaturvedi HK. Primary gastrointestinal lymphoma: 30-year experience at the cancer institute, madras, india. J Surg Oncol 1995;60(1):41-9.

10. Almasri NM, Al-Abbadi M, Rewaily E, Abulkhail A, Tarawneh MS. Primary gastrointestinal lymphomas in Jordan are similar to those in Western countries. Modern Pathol 1997;10(2):137-41.

11. Berger F, Coiffier B, Bonneville C, Scoazec J-Y, Magaud J-P, Bryon PA. Gastrointestinal lymphomas: immunohistologic study of 23 cases. Am J Clin Pathol 1987;88(6):707-12.

12. Grody WW, Magidson J, Weiss L, Hu E, Warnke H, Lewin KJ. Gastrointestinal lymphomas. Immunohistochemical studies on the cell of origin. Am J Surg Pathol 1985;9(5):328-37.

13. Isaacson P, Spencer J. Malignant lymphoma of mucosa-associated lymphoid tissue. Histopathol 1987;11(5):445-62.

14. Mir R, Kahn L, editors. Immunohistochemistry of primary gastrointestinal lymphomas-a study of 38 cases. Laboratory investigation; 1983: Williams \& Wilkins 351 West Camden St, Baltimore, MD 21201-2436.

15. Terada T. Malignant tumors of the small intestine: A histopathologic study of 41 cases among 1,312 consecutive specimens of small intestine. Int J Clin Exp Pathol 2012;5(3):203.

How to cite this article: Rajeswari T., Rajalakshmi V. Gastrointestinal lymphomas- A clinicopathological study in a tertiary care centre. J Diagn Pathol Oncol 2018;3(4):274-80. 